\title{
Statins: Cardiovascular Risk Reduction in Percutaneous Coronary Intervention-Basic and Clinical Evidence of Hyperacute Use of Statins
}

\author{
Enrique C. Morales-Villegas, ${ }^{1}$ Germano Di Sciascio, ${ }^{2,3}$ and Carlo Briguori ${ }^{4}$ \\ ${ }^{1}$ Centro de Investigación Cardiometabólica, Quinta Avenida 702-210, Frac. Agricultura, Aguascalientes, 20234 México, AGS, Mexico \\ ${ }^{2}$ Università Campus Bio-Medico di Roma, 00128 Rome, Italy \\ ${ }^{3}$ Università di Roma "La Sapienza", 00185 Rome, Italy \\ ${ }^{4}$ Clinica Mediterranea, Laboratorio di Emodinamica e Cardiologia Interventistica, 80122 Naples, Italy
}

Correspondence should be addressed to Enrique C. Morales-Villegas, drmorvi@prodigy.net.mx

Received 26 November 2010; Revised 12 January 2011; Accepted 17 January 2011

Academic Editor: Kazuko Masuo

Copyright ( 2011 Enrique C. Morales-Villegas et al. This is an open access article distributed under the Creative Commons Attribution License, which permits unrestricted use, distribution, and reproduction in any medium, provided the original work is properly cited.

\begin{abstract}
Reduction of LDL-cholesterol concentration in serum, blocking the isoprenylation of GTPases and the activation of myocyteprotective enzyme systems are three mechanisms that currently explain the lipid and non-lipid effects of statins. However, the decrease of LDL-cholesterol, the reduction of inflammation biomarkers and even the atheroregresion, as surrogate effects to the mechanisms of action of statins would be irrelevant if not accompanied by a significant decrease in the incidence of cardiovascular events. Statins like no other pharmacological group have proven to reduce the incidence of cardiovascular events and prolong life in any clinical scenario. This article review the basic and clinical evidence that support a new indication for HMG-CoA reductase inhibitors "pharmacological myocardial preconditioning before anticipated ischemia" or hyperacute use of statins in subjects with any coronary syndrome eligible for elective, semi-urgent or primary percutaneous coronary intervention: ARMYDA-Original, NAPLES I-II, ARMYDA-ACS, ARMYDA-RECAPTURE, Non-STEMI-Korean, Korean-STEMI trials.
\end{abstract}

\section{Introduction}

The inhibitors of Hydroxy Methyl Glutaryl-Coenzyme A Reductase (I-HMG-CoA-R) or statins have become the cornerstone of drug therapy that aimed at reducing cardiovascular risk. Statins are the pharmacological group with the highest reduction power of the serum LDL cholesterol concentration, apart from other lipid and pleiotropic actions. Therefore, their therapeutic efficacy can be explained if we remember that LDL cholesterol modified by oxidation becomes an epitope, which provokes along with other endothelial-vascular lesion factors, a pathological sequence with atherosis, endothelial activation-dysfunction lesion, atherosclerosis, and atherothrombosis. Thus, statins have become the most important pharmacological weapon for cardiovascular risk reduction when associated to atherosclerosis.

This paper reviews the most important pharmacological properties of statins, starting with new information on the mechanisms of action and effects that explain the reduction of LDL cholesterol concentration in serum, as well as nonlipid or pleiotropic effects. These basic concepts will be the foundations that will lead us to a better understanding of the impact of statins in new clinical applications, specially focusing on the role they play as reducers of Percutaneous Coronary Intervention (PCI) complications in individuals with stable and unstable coronary syndromes with and without ST segment elevation.

\section{Statins: Mechanism of Action}

The first statin extracted from Penicillium citrinum was discovered by Dr. Akira Endo in the 70s. Based on the knowledge of cholesterol synthesis from acyl and acetylCoA, Endo showed that compactin when competing with the HMG-CoA was an inhibitor of the enzyme that regulates cholesterol synthesis. Statins specifically compete with 
HMG-CoA for the catalytic site of its reductase (HMGCoA-R). This competition inhibits the metabolic pathway of HMG-CoA into mevalonate, a precursor molecule for the synthesis of cholesterol and other molecules such as the isoprenoids, Farnesyl and Geranyl Pyrophosphates [1, 2]. Endo's discovery was complemented and made clinically relevant by the studies of Joseph Goldstein and Michael Brown. Both researchers discovered the cellular receptor for LDL cholesterol (LDL-R) and described three concepts that would revolutionize medicine. Such concepts gave them a Nobel Prize in 1985 [3]. These "classical" concepts of and new data on the mobilization of intracellular cholesterol are presented as follows (see Figure 1).

(a) Receptor-Mediated Endocytosis. Each LDL macromolecule contains an average of 1500 molecules of cholesteryl ester; it gets into cells through the existence of LDL-R. These receptors are glycoproteins with 5 domains, embedded in convex structures of the cell membrane, formed by clathrin protein, and called "clathrin-coated pits." These structures serve as gathering places for cell surface receptors aimed at endocytosis. Once the LDL cholesterol is taken up by the LDL-R, an endocytic vesicle called endosome or receptosome is formed. Within the cell the LDL-R leaves the endosome and returns to the cell membrane; this dissociation is favored by a decrease in $\mathrm{pH}$ within the endosome. The LDL is transferred from the endosomes to the lysosomes and within them; both lipids and apoproteins are hydrolyzed, the first one into nonesterified cholesterol and the second into amino acids [3-5].

(b) Self-Regulation of the Receptor. Nonesterified cholesterol due to its being hydrophobic cannot move freely within the cell cytoplasm. The transport means of nonesterified cholesterol from the lysosome to the cell membranes was recently described by Brown and Goldstein and has been called "hydrophobic handoff mechanism." In this process proteins Niemann Pick 2 and 1 form a "hydrophobic core" that contains and carries the nonesterified cholesterol. The concentration of cholesterol in cell membranes, including the membrane of the Sarcoplasmic Reticulum/Golgi Apparatus system, is the signal to regulate the connection between the transcription factor, Sterol Regulatory Element Binding Protein (SREBP), and its anchor protein SREBP-Cleavage Activating Protein (SCAP). Cytoplasmic sequestration of SREBP by SCAP prevents the synthesis of LDL-R and other enzymes involved in cholesterol synthesis, especially HMG-CoA-R. The higher the concentration of cholesterol in cell membranes, the greater the inhibition of the synthesis of LDL-R. Free nonesterified cholesterol in the cytoplasm is reesterified by Acyl-CoA Cholesterol Acyl Transferase 1 (ACAT1) and then it can be integrated to the cellular metabolism [3-6].

(c) Recycling of the Receptor. The LDL-R plays an insideout cell cycle every 10 minutes, so each LDL-R makes more than hundred cycles during its average 20-hour life. The cell cycle of the LDL-R can be interrupted by the action of the recently discovered Proprotein Convertase Subtilisin Kexin type 9 (PCSK9) [7].

Thus, by inhibiting the HMG-CoA-R, the mechanisms that allow statins to reduce concentrations of cholesterol in serum are the following: (a) reduction of cholesterol hepatic synthesis and therefore a reduction in the synthesis of VLDL, an IDL and LDL precursor; (b) reduction in the concentration of cholesterol in the membranes of the hepatocyte and increased transcription, synthesis and expression of LDL-R with an affinity for IDL (in apo-E) and LDL (in apo-B100); (c) increase in hepatic uptake of IDL and LDL and cholesterol hepatobiliary elimination $[8,9]$. The cholesterol-lowering power of statins is directly related to the number of links they establish with the catalytic site of HMGCoA-R; atorvastatin establishes 8 links while rosuvastatin 9, and therefore the inhibition coefficients of $50 \%$ (IC-50) of the enzymatic action of HMG-CoA-R are of 5.4 and 8.2 nanomoles, respectively [8-12].

\section{Statins-Effects on Cholesterol, Biomarkers of Inflammation, and Myocyte Protection: Cholesterol Reduction}

The average reduction of cholesterol in serum is a function of the statin and its dosage; $10 \mathrm{mg}$ of atorvastatin or rosuvastatin $5 \mathrm{mg}$ achieve an average reduction of $35 \%$ in the baseline value of LDL cholesterol, while the maximum therapeutic doses $80 \mathrm{mg}$ and $40 \mathrm{mg}$, respectively, produce an average reduction of $50 \%$ and $55 \%$. This effect is independent of the hydrophilicity (facilitated diffusion by Organic Anion Transporters of Polypeptides or OATP) or lipophilicity (direct diffusion) of the statin. These data allows us to calculate the optimal therapeutic dose of a statin according to baseline LDL cholesterol, the goal regarding the cardiovascular risk level and the treatment gap [13-15].

Reduction in Inflammation Biomarkers. Statins not only reduce the concentration of LDL cholesterol in serum, as mentioned above, inhibition of the synthesis of mevalonate by statins also blocks the synthesis of isoprenoids (Farnesyl and Geranyl Pyrophosphates). In the phenomenon of endothelial activation, isoprenoids play a very important role $[16,17]$; in endothelial cells, binding of oxidized LDL cholesterol to its LOX Receptor activates the expression of its inflammatory phenotype; during such process, the intracellular switch is the isoprenylation of small $G$ type proteins (smgs). These proteins are called $G$ for their guanosine content, when nonactive, smgs are "floating" in the cellular cytoplasm linked to Guanosine Diphosphate (GDP), and its activation depends on the presence of isoprenoids and the Guanosine Exchange Factor (GEF). With the participation of both molecules, the GDP acquires a phosphate group and becomes Guanosine Triphosphate (GTP); thus, the inactive smgs acquire the characteristic of GTPases, migrate, anchor themselves to the cell membrane, and exert their phosphorylating action on various substrates for activation of multiple enzymatic cascades. GTPases are divided into several enzyme families, the most important are 


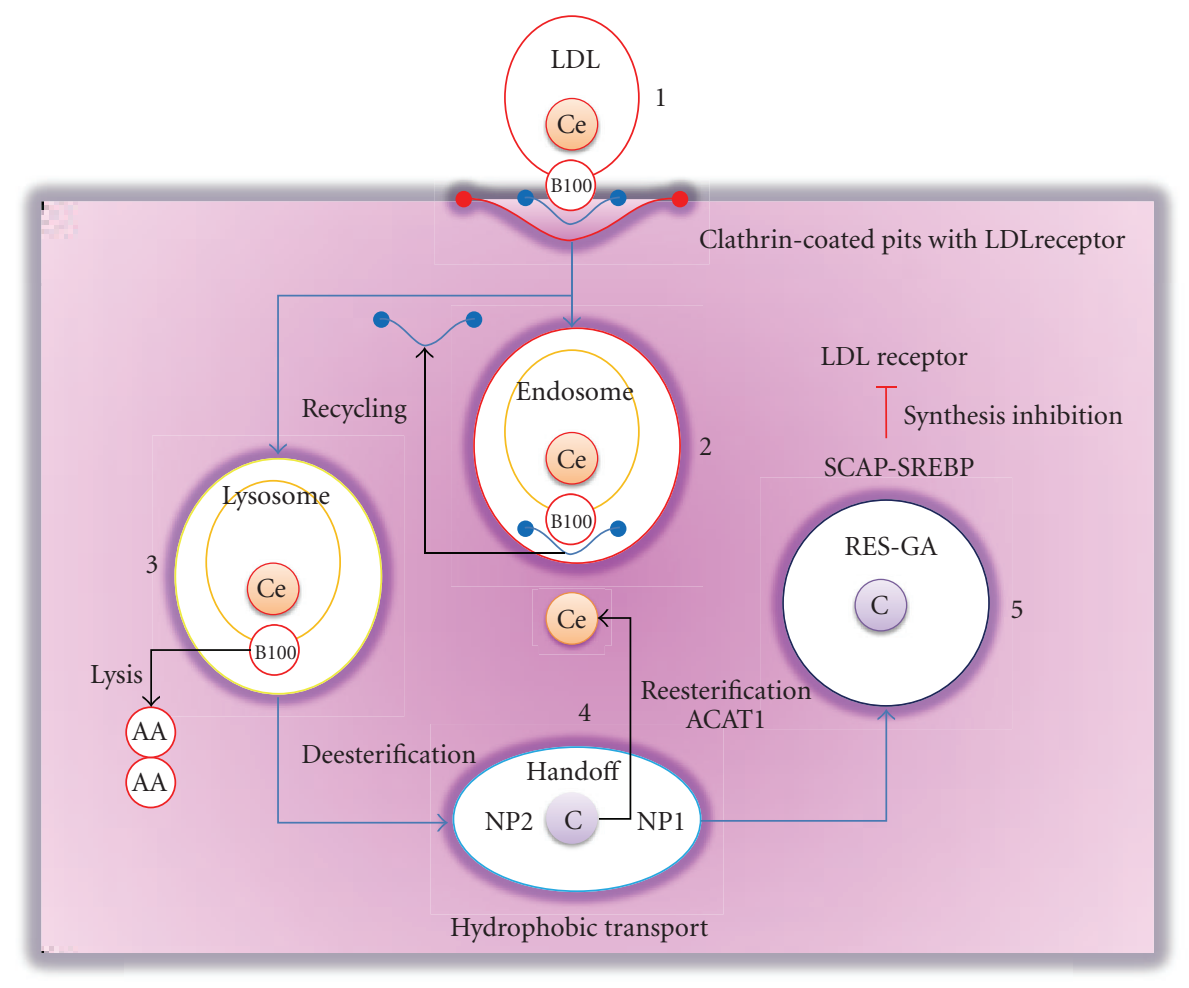

Figure 1: Regulation of LDL-R in 5 steps. Step 1. The LDL is recognized in apo-B100 by the LDL-R located in the membrane structures "clathrin-coated pits." Step 2. It forms an endocytic vesicle or endosome containing LDL and LDL-R, the LDL-R is dissociated through lowering of the $\mathrm{pH}$ within the endosome, and the LDL is transferred to the lysosomes. Step 3. In lysosomes, apo-B100 is hydrolyzed into amino acids and cholesteryl ester is deesterified by enzymatic hydrolysis. Step 4. Nonesterified cholesterol (hydrophobic) is transported to the cell membranes by the "hydrophobic handoff mechanism"; in this mechanism Niemann Pick 2 and 1 proteins form a hydrophobic core containing nonesterified cholesterol. Step 5. Nonesterified cholesterol is transferred by the binomial NP2-NP1 to cell membranes, its concentration in the Sarcoplasmic Reticulum/Golgi Apparatus membranes is the signal that inhibits the dissociation of SCAP-SREBP and thus blocks the synthesis of LDL-R.

the so-called Ras, Rho, and Rab, each stimulating different cellular processes involved in the inflammatory process (e.g., the smg Ras modulate cell division and growth, the smg Rho proteins activate the cell cytoskeleton, and the smg Rab regulate intracellular vesicular movement) (see Figure 2) $[18,19]$.

Thus, inhibition of isoprenoid synthesis by statins reduces isoprenylation of smgs proteins and blocks in different degrees the inflammatory response initiated by oxidized LDL cholesterol binding to LOX-R. Inflammatory endothelial activation initiated by the binding of other ligands to their receptors (e.g., angiotensin II to AT1-R or AGEs to RAGEs) is also generated from a process of smgs and G proteins isoprenylation; this explains why the antiinflammatory effect of statins is not proportional to the reduction of LDL cholesterol; its anti-inflammatory capacity goes beyond this fact due to its potential to inhibit the switch of inflammatory endothelial activation, regardless of the stimulus [20,21].

Multiple in vitro evidence has been published, in vivo in experimental animals and in vivo in individuals with atherosclerosis such evidence has shown that statins attenuate vascular endothelial inflammatory process of atherosclerosis itself. This endothelium-vascular inflammatory attenuation is independent but synergistic with LDL cholesterol reduction. The following are among the most important pieces of evidence. Dr. Jain's team at Harvard proved in vitro that statins promote on endothelial cells the expression of Kruppel-Like Factor 2 (KLF2), transcription factor for the synthesis of eNOS and thrombomodulin [22]. Thus, statins stimulate the synthesis of eNOS, an enzyme responsible for the production of nitric oxide, which among its many actions promotes on the endothelial cell the intracytoplasmic sequestration of the transcription factor NF $\kappa$ B (group of "master" transcription factors of the inflammatory response). The translation in vivo, in the experimental animal, of the anti-inflammatory effect of statins has been published by several researchers. For example, in the animal model of aortocoronary atherosclerosis in mice, when blindly compared with placebo, statins decrease "acutely" the monocyte infiltration into atherosclerotic aortocoronary areas [23]. This phenomenon is equivalent to the in vivo demonstration in humans of "acute" reduction of the inflammatory activity in aortas with atherosclerosis in subjects treated with statins. By using 18FDG-PET, it has been shown that the administration of atorvastatin 


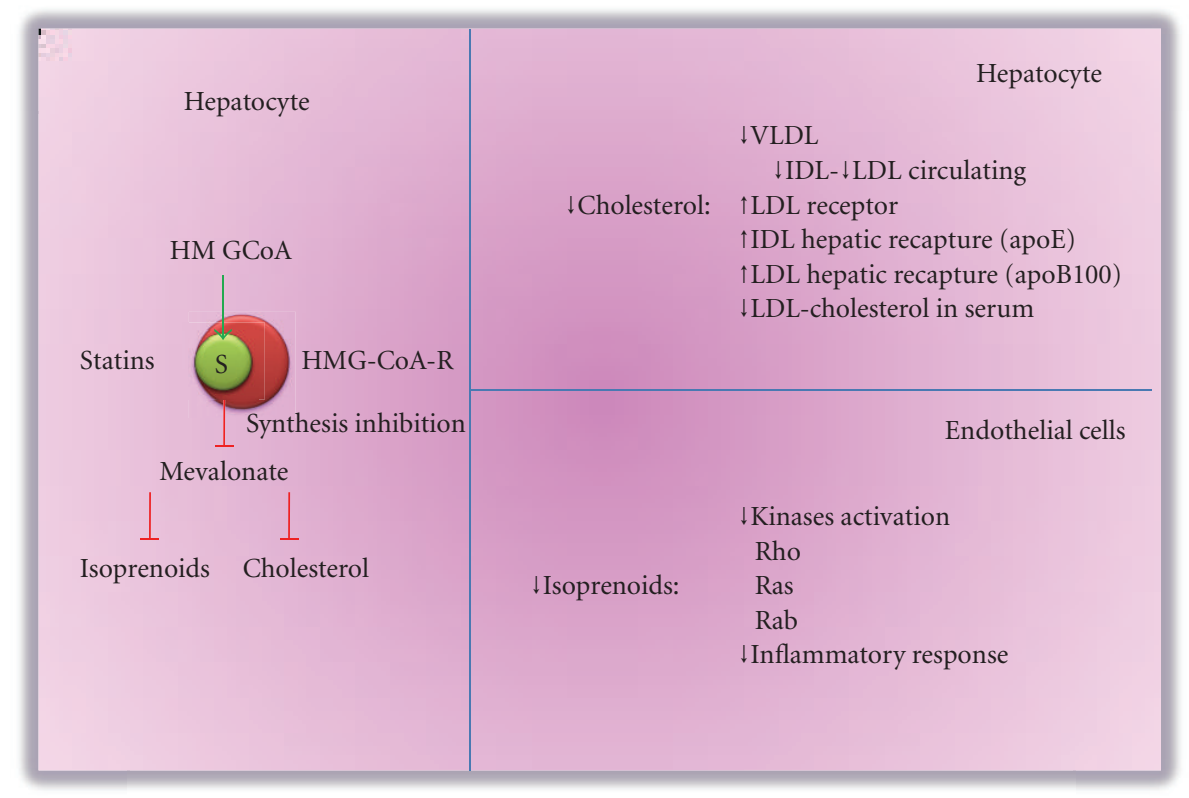

FIGURE 2: Statins reduce cholesterol, and isoprenoids synthesis. The statins inhibit HMG-CoA-R and block the synthesis of mevalonate, cholesterol, and isoprenoids. In the hepatocyte, the reduction in cholesterol synthesis determines a reduction in VLDL synthesis and increase in the synthesis of LDL-R; thus, the reduced production of VLDL, IDL, and LDL and increased elimination of circulating IDL, and LDL, explain the reduction in LDL concentration. In the endothelial cells the reduction in the synthesis of isoprenoids determines a reduction of the inflammatory response mediated by inactivation of smgs from different families (Rho, Ras, Rab).

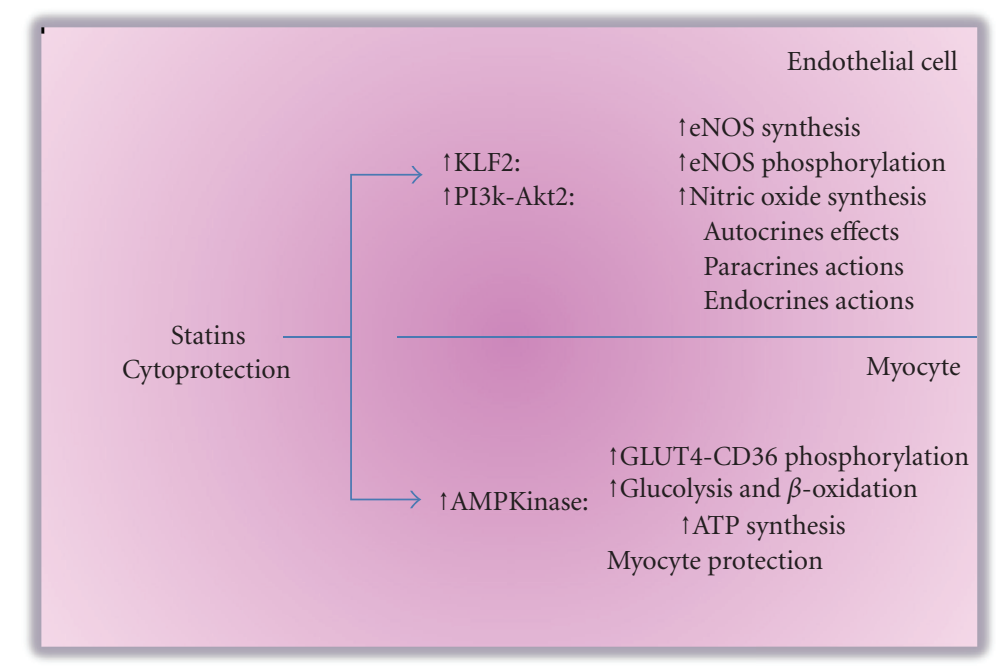

FIGURE 3: Statins, mechanisms, and myocyte-protective effects. Statins increase the expression of KLF2 and eNOS synthesis and also increase the activation of eNOS and nitric oxide production. In the myocyte the activation of AMPK increases the income and energy substrate utilization, as well as the production of ATP.

significantly reduced inflammatory activity in human aortas with atherosclerosis; this change in inflammatory activity occurs within days and was not associated with significant changes in the concentration of LDL cholesterol in serum [24].

Myocyte Protection. Statins in experimenting animals have shown a myocyte-protective effect, this effect is independent of LDL-cholesterol reduction and anti-inflammatory effect and have been associated with the activation of two cellular protective enzyme systems, the Reperfusion Ischemic Salvage Kinases pathway (RISK pathway) and the AMP-activated Kinase (see Figure 3) (AMPK) [25-30].

RISK Pathway. Nitric oxide production by activation of enzymatic cascade PI3Kinase-Akt2-eNOS is a physiological 


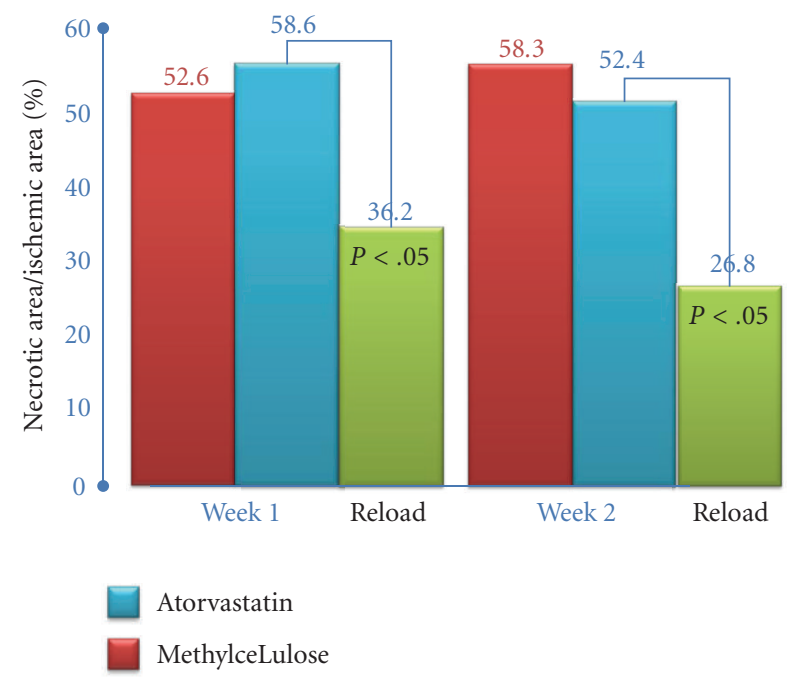

FIgURE 4: Statins and recapture of the RISK pathway. This modified graphic of Mensah's work, shows how the quotient (necrosis/ischemia) is similar in rats treated for 1 or 2 weeks with methylcellulose (red bars) or atorvastatin (blue bars). This loss of myocyte-protective effect is "recaptured" significantly with the reload of atorvastatin (green bars).

process of cell protection against ischemia and statins have been proven to potentiate this process. However, Yellon and his colleagues have shown in experimental animals that "chronic" experimental administration of statins prevents the production of nitric oxide through RISK pathway. This inhibition is due to the overexpression of the Phosphatase Tensin (PTEN) with an antagonistic action towards PI3Kinase. This blockade of the RISK pathway can be recaptured with the administration of a statin reload [31]. Mensah demonstrated in experimental rats subjected to myocardial ischemia and postischemia reperfusion that the quotient (myocardial necrosis/ischemia) after reperfusion was significantly reduced by administration prior to the ischemia of an acute dose (day 1 and day 3 ) of atorvastatin. This myocyte-protective effect was canceled when the statin was administered for longer periods ( 1 and 2 weeks) before induction of myocardial ischemia. The cancellation of the myocyte-protective effect was associated with a significant increase in the concentration of PTEN. The most important finding of this series of experiments was the evidence that, in animals treated for 1 or 2 weeks with atorvastatin, the reload of atorvastatin in day 1 significantly reduced the quotient (myocardial necrosis/ischemia), which, means that it "recaptured the RISK pathway." (see Figure 4) The hypothesis is that statins reload manages to inhibit the expression of PTEN and enhances the expression of PI3Kinase-Akt2-eNOS with increased production of nitric oxide [31]. This evidences provided the rationale and name of the study ARMYDARECAPTURE analyzed as follow.

AMPKinase. This enzyme is considered the energetic switch of the ischemic, cell. In the ischemic cell there is an inversion of the quotient ATP/AMP by increased cytoplasmic concentration of AMP (ADP + ADP $=1$ ATP +1 AMP). The AMP increase is the signal that activates the gamma subunit of the AMPK and initiates multiple phosphorylation substrates (AMPK-kinases). Among the substrates activated by AMPK are the glucose transporters (GLUT4), fatty acid transporters (CD36) and key enzymes of the pathways of glycolysis and beta-oxidation. Thus activation of AMPK increases cellular entry, the use of glucose and free fatty acids, as well as the production of ATP. There is much evidence that molecules such as adiponectin, metformin, and statins are indirect AMPK activators, thereby exercising a myocyte-protective effect, especially in scenarios of myocardial ischemia [28]. To summarize, the RISK pathway and the AMPK are activated by statins in an LDL-independent manner. The RISK pathway increases nitric oxide production and AMPK increases cellular income and utilization of glucose and fatty acids which optimizes the energy efficiency of the ischemic cell [25-31].

\section{Statins: Clinical Effects in Percutaneous Coronary Intervention (Hyperacute Use)}

Based on observational studies, most notably Chang's [32] randomized studies were designed and provided solid evidence resulting in new options for therapeutic use of statins in subjects undergoing elective, semiurgent (12-48 hours of "interventional window"), and primary Percutaneous Coronary Intervention (PCI). The reduction in the risk of Myocardial Infarction-PCI associated (MI-PCI associated) with a statin load prior to PCI is undoubtedly an important therapeutic benefit that is changing the therapeutic approach on the hemodynamics prelude, which will probably give statins a new indication (pharmacologic preconditioning against anticipated myocardial ischemia) [33-42]. The Italian group led by Germano Di Sciascio began, with its publication in 2004, the series of formal clinical studies supporting the concept of myocardial preconditioning by statin against anticipated myocardial ischemia. This series of studies include the following: ARMYDA-Original [34], ARMYDA-CAMs [35], NAPLES I-II [36, 37], ARMYDAACS [38], ARMYDA-RECAPTURE [39], ARMYDA-AMI [40], still under recruitment stage, and the recently published Koreans studies on Non-STEMI [41] and Statin-STEMI [42] (see Table 1).

Before addressing the analysis of these studies, it is important to review the definition of MI-PCI associated, its frequency, and prognosis implications. Since 2007, the diagnosis criteria for MI-PCI associated is 3 times greater than the normal maximum value of CPK-MB and/or troponins (before 2007 the criteria was 2 times more) [43]. The MI-PCI associated is common, its incidence has been reported as high as $70 \%$, and its pathogenesis involves several factors: some of the most important are the endothelial-vascular size and condition of the compromised territory, the spontaneous microembolization, as well as the microembolization induced by the triad catheter-balloonStent with distally compromised microcirculation, collateral circulation, and myocardial ability to respond to trans 
TABLE 1: Randomized trials with statins in percutaneous coronary intervention. This table is a summary of the 8 randomized trials (versus placebo or versus control groups) published with statins in individuals under PCI. All studies except Vaselka's have shown positive results for the use of statins prior to PCI. The results in individuals with elevated CRP before PCI (NAPLES II) and in individuals with ACS (ARMYDA-ACS y ARMYDA-RECAPTURE, ACS soubgroup), are particularly favorable. MI-PCI-A: Myocardial Infarction-PCI associated. MACE: Mayor Adverse Cardiovascular Events. MRI: Myocardial Reperfusion Indicators.

\begin{tabular}{|c|c|c|c|c|}
\hline Trial & \multicolumn{2}{|c|}{ Interventional scenario } & Treatment & Primary end point \\
\hline $\begin{array}{l}\text { ARMYDA-Original } \\
\text { N } 153 \text { naive }(76 / 77)\end{array}$ & & Non-ACS & $\begin{array}{l}\text { Atorvastatin versus placebo } 40 \mathrm{mg} / 7 \\
\text { days pre-PCI }\end{array}$ & $\begin{array}{l}\downarrow \text { MI-PCI-A. CPK-MB > } 2 \mathrm{x} \text { ULN } \\
05.0 \% \text { versus } 18.0 \%(P=.025)\end{array}$ \\
\hline $\begin{array}{l}\text { NAPLES I } \\
\text { N } 451 \text { naive }(226 / 225)\end{array}$ & & Non-ACS & $\begin{array}{l}\text { Various statins versus control } \\
\text { Different doses }>72 \mathrm{hr} \text { pre-PCI }\end{array}$ & $\begin{array}{l}\downarrow \text { MI-PCI-A. CPK-MB }>3 \mathrm{x} \text { ULN } \\
08.0 \% \text { versus } 15.6 \%(P=.012)\end{array}$ \\
\hline $\begin{array}{l}\text { NAPLES II } \\
\text { N } 668 \text { naive }(338 / 330)\end{array}$ & & Non-ACS & $\begin{array}{l}\text { Atorvastatin versus control } \\
80 \mathrm{mg} / 24 \mathrm{hr} \text { pre-PCI }\end{array}$ & $\begin{array}{l}\downarrow \text { MI-PCI-A. CPK-MB > 3x ULN } \\
09.5 \% \text { versus } 15.8 \%(P=.014) \\
\downarrow \text { MI-PCI-A. CPK-MB }>3 x \text { ULN } \\
04.6 \% \text { versus } 16.5 \%(P=.016) \\
\text { (subgroup CRP }>6 \mathrm{mg} / \mathrm{lt})\end{array}$ \\
\hline $\begin{array}{l}\text { ARMYDA-ACS } \\
\text { N } 171 \text { naive }(85 / 86)\end{array}$ & Non-STEMI ACS & & $\begin{array}{l}\text { Atorvastatin versus placebo } \\
120 \mathrm{mg} / 12 \mathrm{hr} \text { pre-PCI }\end{array}$ & $\begin{array}{l}\downarrow \text { MACE day } 30.05 .0 \% \text { versus } \\
17.0 \%(P=.01) \\
\downarrow \text { MI-PCI-A. CPK-MB > 2x ULN } \\
0.5 \% \text { versus } 15.0 \%(P=.04)\end{array}$ \\
\hline $\begin{array}{l}\text { ARMYDA-REC } \\
\text { N } 383 \operatorname{preTx}(192 / 191)\end{array}$ & $\begin{array}{l}\text { Non-STEMI ACS } \\
47 \%\end{array}$ & $\begin{array}{l}\text { Non-ACS } \\
53 \%\end{array}$ & $\begin{array}{l}\text { Atorvastatin versus placebo } \\
120 \mathrm{mg} / 12 \mathrm{hr} \text { pre-PCI }\end{array}$ & $\begin{array}{l}\downarrow \text { MACE day } 30.03 .7 \% \text { versus } \\
09.4 \%(P=.037) . \\
\downarrow \text { MACEs day } 30.03 .3 \% \text { versus } \\
14.8 \%(P=.015)(\text { subgroup ACS })\end{array}$ \\
\hline $\begin{array}{l}\text { Non-STEMI Korean } \\
\text { N } 445 \text { naive }(220 / 225)\end{array}$ & Non-STEMI ACS & & $\begin{array}{l}\text { Rosuvastatin versus control } \\
40 \mathrm{mg} / 16 \mathrm{hr} \text { pre-PCI }\end{array}$ & $\begin{array}{l}\downarrow \text { MI-PCI-A. CPK-MB > 2x ULN. } \\
05.8 \% \text { versus } 11.4 \%(P=.035)\end{array}$ \\
\hline $\begin{array}{l}\text { STEMI Korean } \\
\text { N } 171 \text { naive }(86 / 85)\end{array}$ & STEMI ACS & & $\begin{array}{l}\text { Atorvastatin high versus low dose } \\
80 \mathrm{mg} \text { versus } 10 \mathrm{mg} \text { in primary PCI }\end{array}$ & $\begin{array}{l}\downarrow \text { MACE day } 30.05 .8 \% \text { versus } \\
10.6 \%(P=.26) \\
\uparrow \text { MRIs min } 90 \text { after PCI. All } \\
\text { indicators } P<.05\end{array}$ \\
\hline $\begin{array}{l}\text { Vaselka } \\
\text { N } 200 \text { naive }(100 / 100) \\
\end{array}$ & & Non-ACS & $\begin{array}{l}\text { Atorvastatin versus Control } \\
80 \mathrm{mg} / 48 \mathrm{hr} \text { pre-PCI }\end{array}$ & $\begin{array}{l}\downarrow \text { MI-PCI-A. CPK-MB }>3 \mathrm{x} \text { ULN } \\
10.0 \% \text { versus } 12.0 \%(P=.065)\end{array}$ \\
\hline
\end{tabular}

and postreperfusion ischemia (myocardial preconditioning) [44]. The MI-PCI associated, even if it is only enzymatic, is associated with deterioration in the prognosis; even when the importance of MI-PCI associated has been minimized, the morbidity and mortality in the medium and long term are directly proportional to the magnitude of PCI-related enzyme increase [45].

\section{Clinical Studies in Percutaneous Coronary Intervention}

5.1. ARMYDA-Original. Aware of observational evidence, Germano Di Sciascio leading the group Romano ARMYDA designed the Original ARMYDA study. This pivotal study showed that individuals with stable coronary syndromes, statin-naive, and with indication of elective coronary angioplasty, who received $40 \mathrm{mg}$ of atorvastatin a day, seven days before PCI, underwent a significant reduction of the relative risk of MI-PCI associated (CPK-MB > 2x ULN, 2004 criteria) as compared to those treated with placebo; $18 \%$ in the placebo group versus $5 \%$ in the atorvastatin with $P=.025$ (see Figure 5).

5.2. ARMYDA-CAMs. The substudy ARMYDA-CAMs (Cell Adhesion Molecules) provided a mechanistic explanation for the overall study results of the ARMYDA-Original study. Patty showed that in the arm treated with $40 \mathrm{mg}$ of atorvastatin a day for seven days before PCI, the increase in adhesion molecules (E-selectin and ICAM-1) 24 hours after intervention, was limited significantly $(P=.0001)$ [35]. This finding reflects a facet of the anti-inflammatory effect of statins, which while inhibiting the expression of the transcription factors like $\mathrm{NF} \kappa \mathrm{B}$, decrease endothelial cells synthesis of these adhesion molecules [16-19] (see Figure 6).

5.3. NAPLES I-II. Carlo Briguori, inspired by the results of the pilot study (NAPLES I) [36] and the already mentioned ARMYDA-Original, developed and published in 2009 the results of NAPLES II trial. This relevant study showed that individuals with stable coronary syndromes, statin-naïve, and with indication of elective coronary angioplasty, who received $80 \mathrm{mg}$ of atorvastatin a day, 24 hours before PCI, underwent a significant reduction of the relative risk of MI-PCI associated (CPK-MB > 3x ULN, 2007 criterion) as compared to those treated with placebo, $15.8 \%$ in the placebo group versus $9.5 \%$ in the atorvastatin group with $P=.014$. With this study, the Naples-Milan group suggested that it is possible to shorten the therapeutic window of the statin load from 7 days to 24 hours. The therapeutic result of the statins load was outstanding in the subgroup with positive 


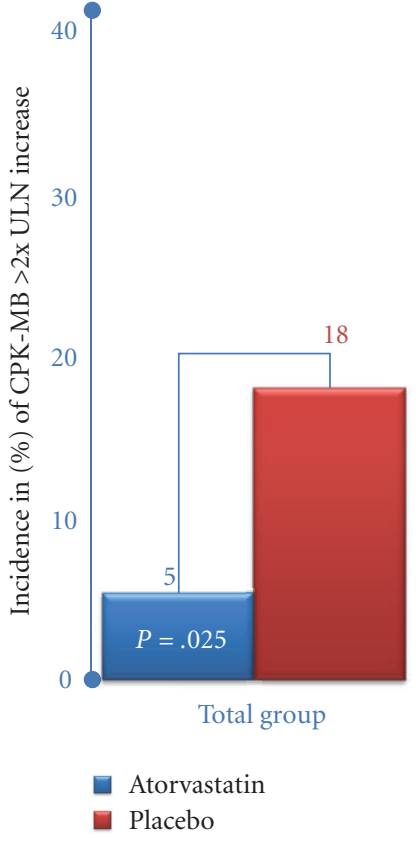

FIgURE 5: ARMYDA-Original study. This modified graphic of the ARMYDA-Original study (Vincenso Pasceri as first author) demonstrated for the first time as a randomized study the favorable effect of statins before PCI. In individuals with stable coronary syndromes, statin-naïve, undergoing elective PCI, the administration of atorvastatin $40 \mathrm{mg} / 7$ days before PCI significantly reduces the incidence of MI-PCI associated (CPK-MB > 2x ULN, 2004 criteria). The MI-PCI associated was $18 \%$ in the placebo group versus $5 \%$ in the atorvastatin group with $P=.025$.

CRP by latex (CRP > $6 \mathrm{mg} / \mathrm{L}$ ) before PCI; in this subgroup, the incidence of MI-PCI associated (CPK-MB > 3x ULN, 2007 criterion) was $16.5 \%$ in the control group compared with $4.6 \%$ in the atorvastatin group with $P=.016$ [37] (see Figure 7).

The results of previous studies in individuals with stable coronary syndromes, motivated the design of ARMYDAACS and later ARMYDA-RECAPTURE, the first in statinnaive individuals and the second in people with chronic statin treatment. These are the two recent studies published by the ARMYDA group, pending the publication of ARMYDA-AMI (Acute Myocardial Infarction).

5.4. ARMYDA-ACS. ARMYDA-ACS study showed that, in individuals with Acute Coronary Syndromes, without STsegment elevation, statin-naïve, and with semiurgent indication of percutaneous coronary angioplasty, who were administrated $120 \mathrm{mg}$ of atorvastatin divided into two doses, a dose of $80 \mathrm{mg}$ twelve hours before and another $40 \mathrm{mg}$ two hours before PCI, there was a significant reduction in the incidence of MACEs or Major Adverse Cardiovascular Events (myocardial infarction, re intervention or cardiovascular death), as compared to those treated with placebo. The relative risk reduction of MACEs reached $88 \% ; 17 \%$ in the placebo group versus $5 \%$ in the atorvastatin group with $P=$ 0.01 . This reduction in MACEs was dominated by a decrease

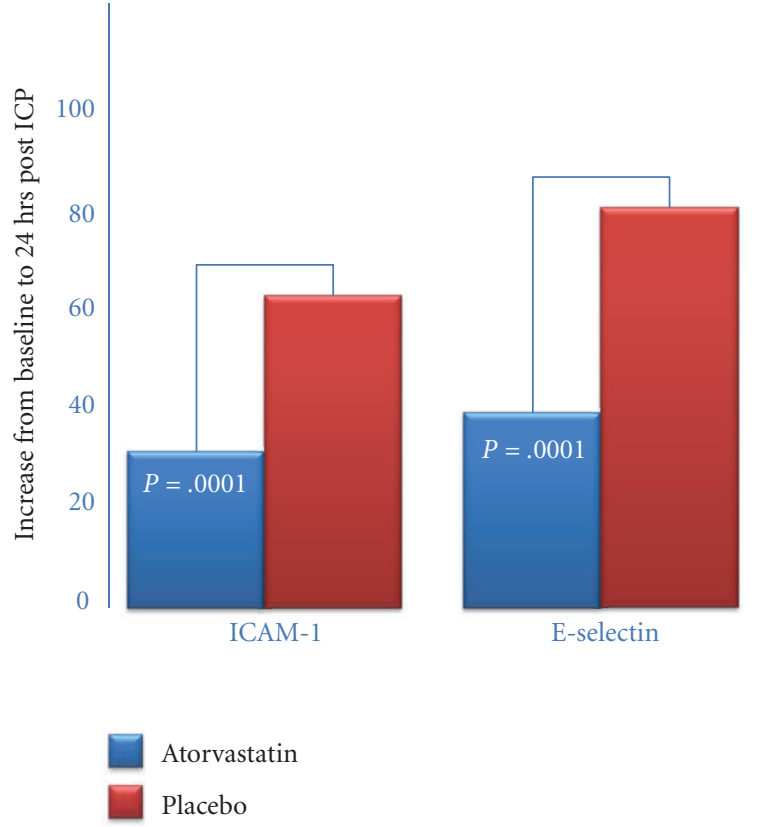

Figure 6: ARMYDA-CAMs study. This modified graphic of the ARMYDA-CAMs study showed that, in a preselected subgroup or the ARMYDA-Original study, in individuals with stable coronary syndromes, statin-naïve, and undergoing elective PCI, the administration of atorvastatin $40 \mathrm{mg} / 7$ days before PCI significantly reduced the percentage of elevation 24 hours after PCI of ICAM and E-selectin. This reduction was not observed with VCAM (not shown in the graphic).

in MI-PCI associated (CPK-MB > 2x ULN, 2004 criterion), $15 \%$ in the placebo group versus $5 \%$ in the atorvastatin group with $P=.04$ [38].

5.5. ARMYDA-RECAPTURE. The ARMYDA-RECAPTURE or RELOAD raised the hypothesis that the recapture of RISK pathway observed in experimental animals could be reproduced in the hospital. This study included individuals with an indication of PCI, who evolved into a stable or unstable coronary syndrome without ST-segment elevation, when chronically treated with statins and LDL $<100 \mathrm{mg} / \mathrm{dl}$. In a design similar to ARMYDA-ACS, this study demonstrated that administration of atorvastatin $120 \mathrm{mg}$, divided into two doses, a dose of $80 \mathrm{mg}$ twelve hours before and another of $40 \mathrm{mg}$ two hours before PCI, significantly reduced the incidence of MACEs (myocardial infarction, reintervention, or cardiovascular death) as compared with those treated with placebo; $9.4 \%$ in the placebo group versus $3.7 \%$ in the atorvastatin group with $P=.037$. This reduction in MACEs was dominated by a decrease in MI-PCI associated (CPK-MB > 3x ULN, 2007 criterion), 8.9\% in the placebo group versus $3.7 \%$ in the atorvastatin group. The therapeutic benefit reached its maximum in the subgroup with unstable coronary syndromes, with an incidence of MACEs greater than $14.8 \%$ in the placebo group versus $3.3 \%$ in the atorvastatin group with $P=.015$, and a Number Needed to 


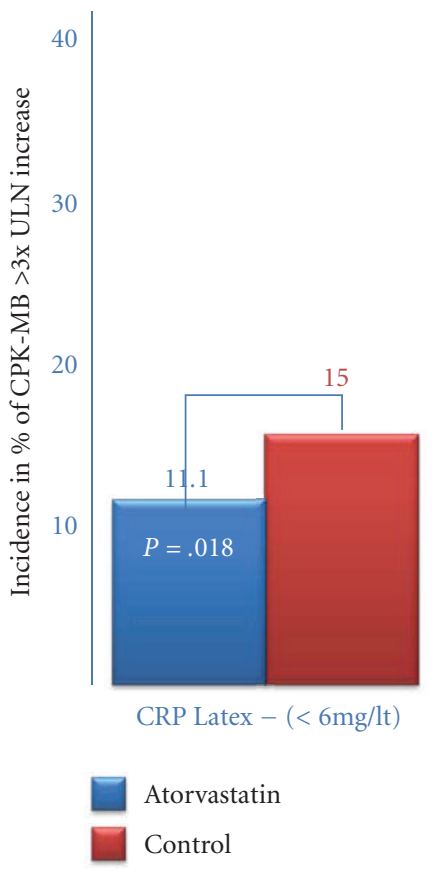

(a)

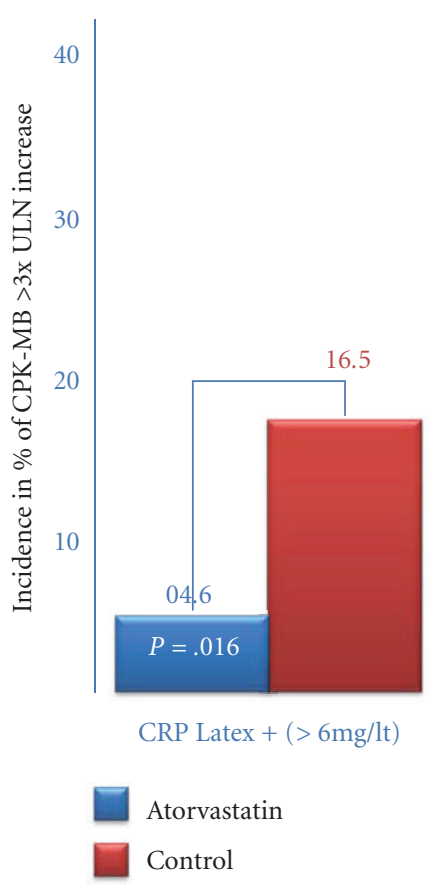

(b)

Figure 7: NAPLES II Study. This modified graphic of the NAPLES II study, confirmed with a randomized study, as compared to a control group, the favorable effect of statins before PCI. In individuals with stable coronary syndromes, statin-naive undergoing elective PCI, the administration of atorvastatin $80 \mathrm{mg} / 24$ hours before PCI significantly reduces the incidence of MI-PCI associated (CPK-MB $>3 \mathrm{x}$ ULN, 2007 criteria). As can be seen, the benefit was especially significant in the subgroup of individuals with CRP > $6 \mathrm{mg} / \mathrm{L}$ before PCI, in this subgroup the incidence of MI-PCI associated was $16.5 \%$ in the control group versus $4.6 \%$ in the atorvastatin group with $P=.016$.

Treat (NNT) of 9 individuals to avoid an MACE, an excellent cost-benefit relation [39] (see Figure 8).

5.6. Non-STEMI and Statin-STEMI Korean Studies. The Korean group led by Ho Yun Kyeong reproduced the results of ARMYDA-ACS. The author used $40 \mathrm{mg}$ of rosuvastatin a day administered an average of 16 hours before PCI, compared with a control group, in individuals with NonSTEMI acute coronary syndromes, and reported a significant reduction in the incidence of MI-PCI associated (CPK-MB $>2 \mathrm{x}$ ULN, 2004 criterion), $11.4 \%$ in placebo group versus $5.8 \%$ in the rosuvastatin group with $P=.035$ [41].

In early 2010 they were also published by a Korean group (the first author was Kim Jung-Sum), the results of StatinSTEMI study which explored the effect of an $80 \mathrm{mg}$ dose versus $10 \mathrm{mg}$ dose of atorvastatin in subjects with STEMI undergoing primary coronary angioplasty. In this study, the primary objective (MACEs at day 30 after PCI) was not positive, but still it did show a trend towards the benefit with the high dose of atorvastatin; MACEs at day $30 \mathrm{after}$ PCI $5.8 \%$ in the $80 \mathrm{mg}$ atorvastatin group versus $10.6 \%$ in the $10 \mathrm{mg}$ atorvastatin group with $P=.026$. This result is probably explained by the size of the sample (171 individuals), the low dose of atorvastatin after PCI $(10 \mathrm{mg} /$ day $)$ and/or the short followup time. However, in the secondary objective (Myocardial Reperfusion Indicators or MRI), there actually was a significant difference favoring the high dose of atorvastatin; corrected TIMI Frame Count (cTFC) 29.6 versus 34.1 with $P=.01$; completed STResolution (cSTR) 61.8 versus 50.6 with $P=.01$; and Myocardial Blush Grade (MBG) 2.2 versus 1.9 with $P=.02$ [42] (see Figure 9).

As a whole, the results of the studies mentioned, all performed in a quintessential endothelial-vascular inflammatory environment, strengthen the presence and importance of nonlipid effects of statins. These results not only support the anti-inflammatory potential of statins due to the effect of "endothelial passivation" but also highlight the myocyte-protective actions of these drugs. From a clinical-therapeutic perspective, the evidence presented here represents a new indication for statins, which although not yet reflected in the guidelines, is changing the therapeutic behavior of Clinical and Interventional Cardiologists at the hemodynamics prelude, because as Stephen Ellis wrote in his editorial for the ARMYDA-RECAPTURE study, "the benefit of statins in PCI, is virtually indisputable and is associated with pleiotropic actions" [29].

\section{Statins and PCI: Abstract}

After compactin, discovered by Akira Endo in the 70s, statins have shown that, when competing with the HMG-CoA by the catalytic site of its reductase, they very effectively inhibit the synthesis of mevalonate, cholesterol, and isoprenoids [1]. This metabolic block favors the reduction in the 


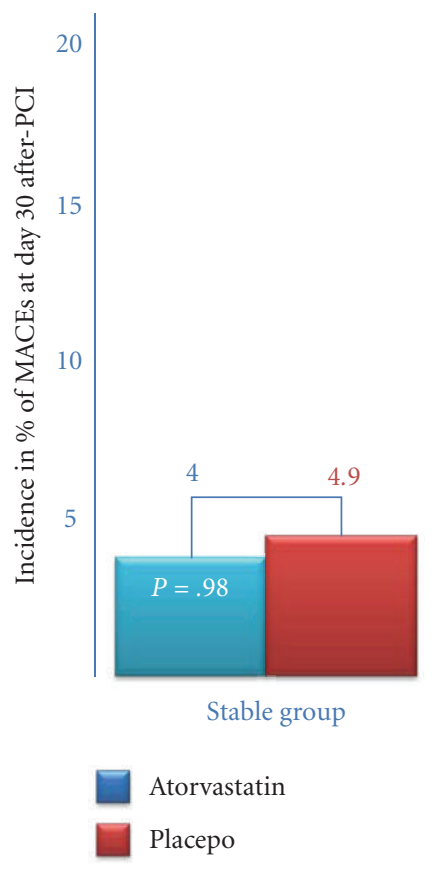

(a)

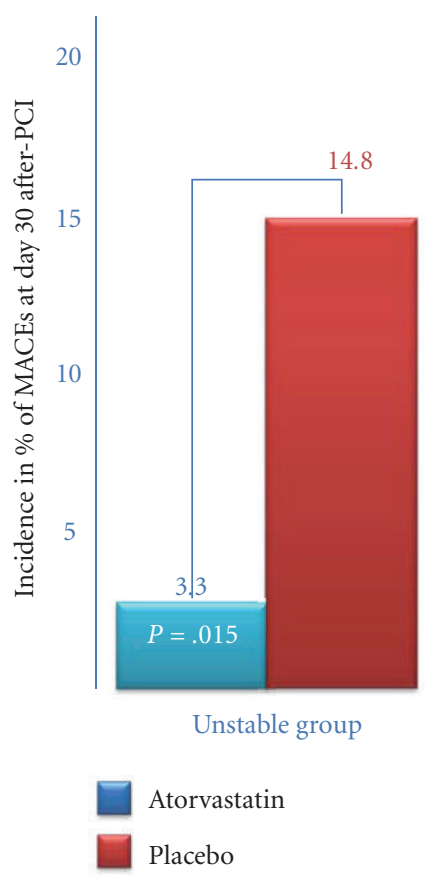

(b)

FIgURE 8: ARMYDA-RECAPTURE study. This modified graphic of the ARMYDA-RELOAD (RECAPTURE) study, showed with a randomized design, as compared to patients treated with placebo, the recapture effect of statins. In individuals with stable and unstable coronary syndromes, chronically treated with statins and LDL $<100 \mathrm{mg} / \mathrm{dl}$, who underwent elective or semiurgent PCI, the administration of $120 \mathrm{mg}$ of atorvastatin before PCI significantly reduces the incidence of MACEs on day 30 after PCI. This benefit was very significant in the subgroup of individuals with unstable coronary syndromes, with an MACEs incidence of $14.8 \%$ in the placebo group versus $3.3 \%$ in the atorvastatin group with $P=.015$.

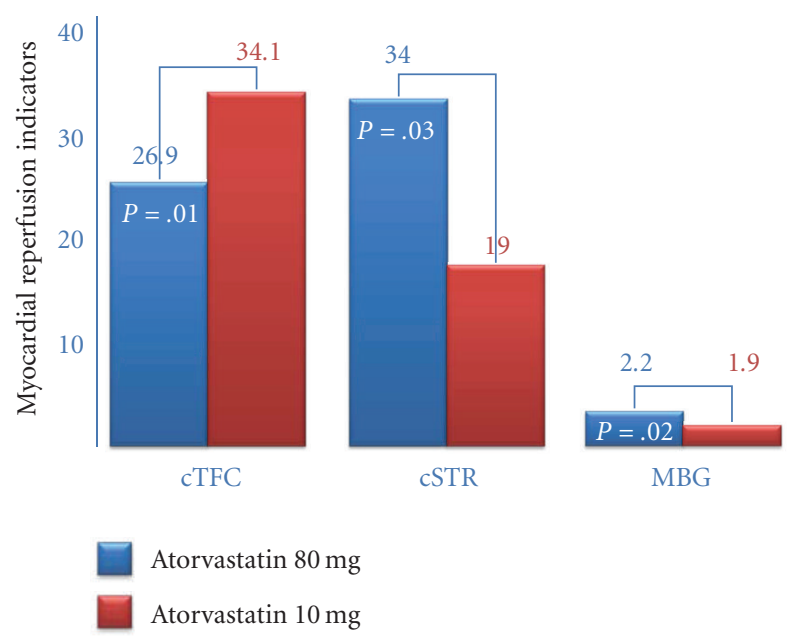

Figure 9: Statin-STEMI study. This modified graphic of the StatinSTEMI study, demonstrated the favorable effect of high doses of atorvastatin before primary PCI on the Myocardial Reperfusion Indicators (cTFC, CSTR, and MBG) after procedure in individuals with STEMI.

cellular synthesis and concentration of cholesterol in the membranes of hepatocytes, this condition being the signal that upregulates the synthesis, expression, and activity of
LDL-R discovered by Brown and Goldstein. The activity of the LDL-R increases the uptake and hepatobiliary elimination of circulating cholesterol this along with the reduction in VLDL synthesis; the mechanisms that explains the effective (35\% to 50\%) reduction in LDL-cholesterol in serum [2-15]. The block of Farnesyl and Geranyl Pyrophosphates synthesis attenuates isoprenylation and activation of GTPases (Ras, Rho and Rab), inhibiting at various degrees, disregarding the external stimulus, the activity of endothelium-vascular inflammatory enzyme cascades [16-24]. Direct activation of PI3K-Akt2-eNOS and indirect activation of AMPK optimizes the supply, uptake and metabolism of energy substrates in the ischemic myocardial cell [25-31]. Thus, the reduction of LDL-cholesterol concentration in serum, blocking the isoprenylation of GTPases and the activation of myocyte-protective enzyme systems are three mechanisms that currently explain the lipid and nonlipid effects of statins [1-31].

As commented in the body of this paper, the decrease of LDL cholesterol, the reduction of inflammation biomarkers and even the atheroregression [46-49], as surrogate effects to the mechanisms of action of statins would be irrelevant if not accompanied by a significant decrease in the incidence of cardiovascular events. Statins like no other pharmacological group have proven to reduce the incidence of cardiovascular events and prolong life in any clinical scenario: in individuals 
of medium or high risk, with no clinical evidence of cardiovascular disease (CTT meta-analysis and ASCOT-LLA, CARDS, JUPITER trials) [50-54]; in individuals with clinical cardiovascular disease, regardless of its manifestation, be it stable coronary syndrome (TNT trial) [55-57], unstable coronary syndrome (MIRACL, PROVE-IT trial) [58-63], carotid vertebral (SPARCL trial) [64]; in subjects with any coronary syndrome eligible for elective, semiurgent, or primary PCI (ARMYDA-Original, NAPLES I-II, ARMYDAACS-RECAPTURE ARMYDA, Non-STEMI-Korean, STEMI Korean trials) [34-42].

Furthermore, the benefit of statins is being studied in other scenarios dominated by inflammation with positive results in rheumatic mitral valve disease [65]. In addition to this, new lines of research are being explored on the effect of statins on endothelial regeneration [66-68]. Finally, inhibition at pre- and posttranslational levels of the PCSK9 is an option that poses an interesting future in the treatment of high LDL cholesterol [69]. Obviously the treatment of other atherogenic lipid fractions (non-HDL cholesterol) and antiatherogenic (HDL cholesterol), as well as other modifiable factors of vascular-endothelial injury (visceral adiposity, arterial hypertension, dysglycemia, etc.), complement the wonderful pharmacological effect of statins [70].

\section{References}

[1] A. Endo, "The discovery and development of HMG-CoA reductase inhibitors," Journal of Lipid Research, vol. 33, no. 11, pp. 1569-1582, 1992.

[2] M. S. Brown and J. L. Goldstein, "A tribute to Akira Endo, discoverer of a "Penicillin" for the cholesterol," Atherosclerosis Supplements, no. 5, pp. 13-16, 2004.

[3] M. S. Brown and J. L. Goldstein, "A receptor-mediated pathway for cholesterol homeostasis," Science, vol. 232, no. 4746, pp. 34-47, 1986.

[4] J. L. Goldstein and M. S. Brown, "Regulation of the mevalonate pathway," Nature, vol. 343, no. 6257, pp. 425-430, 1990.

[5] J. L. Goldstein and M. S. Brown, "The LDL receptor. History of discovery," Arteriosclerosis, Thrombosis, and Vascular Biology, vol. 29, no. 4, pp. 431-438, 2009.

[6] J. L. Goldstein and M. S. Brown, Hidrophobic Handoff Mechanism, Nobel Laureate Lecture, American Heart Association Meeting, Chicago, Ill, USA, 2010.

[7] B. Cariou, K. Ouguerram, Y. Zaïr et al., "PCSK9 dominant negative mutant results in increased LDL catabolic rate and familial hypobetalipoproteinemia," Arteriosclerosis, Thrombosis, and Vascular Biology, vol. 29, no. 12, pp. 2191-2197, 2009.

[8] H. N. Ginsberg, N. A. Le, M. P. Short, R. Ramakrishnan, and R. J. Desnick, "Suppression of apolipoprotein B production during treatment of cholesteryl ester storage disease with lovastatin. Implications for regulation of apolipoprotein B synthesis," Journal of Clinical Investigation, vol. 80, no. 6, pp. 1692-1697, 1987.

[9] Y. Arad, R. Ramakrishnan, and H. N. Ginsberg, "Lovastatin therapy reduces low density lipoprotein apoB levels in subjects with combined hyperlipidemia by reducing the production of apoB-containing lipoproteins: implications for the pathophysiology of apoB production," Journal of Lipid Research, vol. 31, no. 4, pp. 567-582, 1990.

[10] E. S. Istvan and J. Deisenhofer, "Structural mechanism for statin inhibition of HMG-CoA reductase," Science, vol. 292, no. 5519, pp. 1160-1164, 2001.

[11] F. McTaggart, L. Buckett, R. Davidson et al., "Preclinical and clinical pharmacology of rosuvastatin, a new 3-hydroxy-3methylglutaryl coenzyme A reductase inhibitor," American Journal of Cardiology, vol. 87, supplement, pp. 28B-32B, 2001.

[12] G. A. Holdgate, W. H. J. Ward, and F. McTaggart, "Molecular mechanism for inhibition of 3-hydroxy-3-methylglutaryl CoA (HMG-CoA) reductase by rosuvastatin," Biochemical Society Transactions, vol. 31, no. 3, pp. 528-531, 2003.

[13] P. H. Jones, M. H. Davidson, E. A. Stein et al., "Comparison of the efficacy and safety of rosuvastatin versus atorvastatin, simvastatin, and pravastatin across doses (STELLAR* trial)," American Journal of Cardiology, vol. 92, no. 2, pp. 152-160, 2003.

[14] J. M. McKenney, P. H. Jones, M. A. Adamczyk, V. A. Cain, B. S. Bryzinski, and J. W. Blasetto, "Comparison of the efficacy of rosuvastatin versus atorvastatin, simvastatin, and pravastatin in achieving lipid goals: results from the STELLAR trial," Current Medical Research and Opinion, vol. 19, no. 8, pp. 689698, 2003.

[15] S. J. Nicholls, G. Brandrup-Wognsen, M. Palmer, and P. J. Barter, "Meta-analysis of comparative efficacy of increasing dose of atorvastatin versus rosuvastatina versus simvastatin on lowering levels of atherogenic lipids (from VOYAGER)," American Journal of Cardiology, vol. 105, no. 1, pp. 69-76, 2010.

[16] P. J. Casey, "Protein lipidation in cell signaling," Science, vol. 268, no. 5208, pp. 221-225, 1995.

[17] F. L. Zhang and P. J. Casey, "Protein prenylation: molecular mechanisms and functional consequences," Annual Review of Biochemistry, vol. 65, pp. 241-269, 1996.

[18] J. K. Liao, "Isoprenoids as mediators of the biological effects of statins," Journal of Clinical Investigation, vol. 110, no. 3, pp. 285-288, 2002.

[19] W. Dichtl, J. Dulak, M. Frick et al., "HMG-CoA reductase inhibitors regulate inflammatory transcription factors in human endothelial and vascular smooth muscle cells," Arteriosclerosis, Thrombosis, and Vascular Biology, vol. 23, no. 1, pp. 58-63, 2003.

[20] S. I. McFarlane, R. Muniyappa, R. Francisco, and J. R. Sowers, "Clinical review 145: pleiotropic effects of statins: lipid reduction and beyond," Journal of Clinical Endocrinology and Metabolism, vol. 87, no. 4, pp. 1451-1458, 2002.

[21] J. K. Liao and U. Laufs, "Pleiotropic effects of statins," Annual Review of Pharmacology and Toxicology, vol. 45, pp. 89-118, 2005.

[22] S. Sen-Banerjee, S. Mir, Z. Lin et al., "Kruppel-like factor 2 as a novel mediator of statin effects in endothelial cells," Circulation, vol. 112, no. 5, pp. 720-726, 2005.

[23] M. F. Kircher, J. Grimm, F. K. Swirski et al., "Noninvasive in vivo imaging of monocyte trafficking to atherosclerotic lesions," Circulation, vol. 117, no. 3, pp. 388-395, 2008.

[24] J. H. F. Rudd, F. Hyafil, and Z. A. Fayad, "Inflammation imaging in atherosclerosis," Arteriosclerosis, Thrombosis, and Vascular Biology, vol. 29, no. 7, pp. 1009-1016, 2009.

[25] R. M. Bell and D. M. Yellon, "Atorvastatin, administered at the onset of reperfusion, and independent of lipid lowering, protects the myocardium by up-regulating a pro-survival 
pathway," Journal of the American College of Cardiology, vol. 41, no. 3, pp. 508-515, 2003.

[26] A. Prasad, G. W. Stone, D. R. Holmes, and B. Gersh, "Reperfusion injury, microvascular dysfunction, and cardioprotection: the "dark side" of reperfusion," Circulation, vol. 120, no. 21, pp. 2105-2112, 2009.

[27] A. Ludman, V. Venugopal, D. M. Yellon, and D. J. Hausenloy, "Statins and cardioprotection-more than just lipid lowering?" Pharmacology and Therapeutics, vol. 122, no. 1, pp. 3043, 2009.

[28] L. H. Young, "AMP-activated protein kinase conducts the ischemic stress response orchestra," Circulation, vol. 117, no. 6, pp. 832-840, 2008.

[29] S. G. Ellis and S. Anwaruddin, "Recapturing the magic. Revisiting the pleiotropic effects of statins in percutaneous coronary revascularization," Journal of the American College of Cardiology, vol. 54, no. 6, pp. 566-568, 2009.

[30] D. J. Hausenloy and D. M. Yellon, "Cell membrane repair as a mechanism for ischemic preconditioning?" Circulation, vol. 121, no. 23, pp. 2547-2549, 2010.

[31] K. Mensah, M. M. Mocanu, and D. M. Yellon, "Failure to protect the myocardium against ischemia/reperfusion injury after chronic atorvastatin treatment is recaptured by acute atorvastatin treatment: a potential role for phosphatase and tensin homolog deleted on chromosome ten?" Journal of the American College of Cardiology, vol. 45, no. 8, pp. 1287-1291, 2005.

[32] S. M. Chang, N. Yazbek, and N. M. Lakkis, "Use of statins prior to percutaneous coronary intervention reduces myonecrosis and improves clinical outcome," Catheterization and Cardiovascular Interventions, vol. 62, no. 2, pp. 193-197, 2004.

[33] A. Nusca, R. Melfi, G. Patti, and G. Di Sciascio, "Statin loading for acute coronary syndromes," Current Opinion in Cardiology, vol. 25, no. 4, pp. 373-378, 2010.

[34] V. Pasceri, G. Patti, A. Nusca, C. Pristipino, G. Richichi, and G. Di Sciascio, "Randomized trial of atorvastatin for reduction of myocardial damage during coronary intervention: results from the ARMYDA (Atorvastatin for Reduction of MYocardial Damage during Angioplasty) study," Circulation, vol. 110, no. 6, pp. 674-678, 2004.

[35] G. Patti, M. Chello, V. Pasceri et al., "Protection from procedural Myocardial injury by atorvastatin is associated with lower levels of adhesion molecules after percutaneous coronary intervention. Results from the ARMYDA-CAMs (Atorvastatin for Reduction of Myocardial Damage during AngioplastyCell Adhesion Molecules)," Journal of the American College of Cardiology, vol. 48, no. 8, pp. 1560-1566, 2006.

[36] C. Briguori, A. Colombo, F. Airoldi et al., "Statin administration before percutaneous coronary intervention: impact on periprocedural myocardial infarction," European Heart Journal, vol. 25, no. 20, pp. 1822-1828, 2004.

[37] C. Briguori, G. Visconti, A. Focaccio et al., "Novel Aproaches for Preventing or Limiting Events (Naples) II trial. Impact of a single high loading dose of atorvastatin on periprocedural myocardial infarction," Journal of the American College of Cardiology, vol. 54, no. 23, pp. 2157-2163, 2009.

[38] G. Patti, V. Pasceri, G. Colonna et al., "Efficacy of atorvastatin reload in patients on chronic statin therapy undergoing percutaneous coronary intervention. Results of the ARMYDARECAPTURE randomized trial," Journal of the American College of Cardiology, vol. 49, no. 12, pp. 1272-1278, 2007.

[39] G. Di Sciascio, G. Patti, V. Pasceri, A. Gaspardone, G. Colonna, and A. Montinaro, "Efficacy of Atorvastatin Reload in Patients on Chronic Statin Therapy Undergoing Percutaneous Coronary Intervention. Results of the ARMYDA-RECAPTURE (Atorvastatin for Reduction of Myocardial Damage During Angioplasty) Randomized Trial," Journal of the American College of Cardiology, vol. 54, no. 6, pp. 558-565, 2009.

[40] G. Di Sciascio, "Personal communication".

[41] K. H. Yun, M. H. Jeong, S. K. Oh et al., "The beneficial effect of high loading dose of rosuvastatin before percutaneous coronary intervention in patients with acute coronary syndrome," International Journal of Cardiology, vol. 137, no. 3, pp. 246$251,2009$.

[42] J. S. Kim, J. Kim, D. Choi et al., "Efficacy of high-dose atorvastatin loading before primary percutaneous coronary intervention in ST-segment elevation myocardial infarction," American College of Cardiology Interview, vol. 3, no. 3, pp. 332$339,2010$.

[43] K. Thygesen, J. S. Alpert, and H. D. White, "On behalf of the Joint ESC/ACCF/AHA/WHF Task Force for the Redifinition of Myocardial Infarction. Universal definition of myocardial infarction," European Heart Journal, vol. 28, pp. 2535-2538, 2001.

[44] G. Heusch, P. Kleinbongard, D. Böse et al., "Coronary microembolization: from bedside to bench and back to bedside," Circulation, vol. 120, no. 18, pp. 1822-1836, 2009.

[45] A. Prasad, M. Singh, A. Lerman, R. J. Lennon, D. R. Holmes, and C. S. Rihal, "Isolated elevation in troponin T after percutaneous coronary intervention is associated with higher long-term mortality," Journal of the American College of Cardiology, vol. 48, no. 9, pp. 1765-1770, 2006.

[46] S. E. Nissen, E. M. Tuzcu, P. Schoenhagen et al., "Effect of intensive compared with moderate lipid-lowering therapy on progression of coronary atherosclerosis," Journal of the American Medical Association, vol. 291, no. 9, pp. 1071-1080, 2004.

[47] S. E. Nissen, E. M. Tuzcu, P. Schoenhagen et al., "Statin therapy, LDL cholesterol, C-reactive protein, and coronary artery disease," The New England Journal of Medicine, vol. 352, no. 1, pp. 29-38, 2005.

[48] S. E. Nissen, S. J. Nicholls, I. Sipahi et al., "Effect of very high-intensity statin therapy on regression of coronary atherosclerosis: the ASTEROID trial," Journal of the American Medical Association, vol. 295, no. 13, pp. 1556-1565, 2006.

[49] J. Rodés-Cabau, J. C. Tardif, M. Cossette et al., "Acute effects of statin therapy on coronary atherosclerosis following acute coronary syndromes," American Journal of Cardiology, vol. 104, no. 6, pp. 750-757, 2009.

[50] Cholesterol Treatment Trialist (CTT) Collaborators, "Efficacy and safety of cholesterol-lowering treatment: prospective meta-analysis of data from 90056 participants in 14 randomized trials of statins," The Lancet, vol. 366, pp. 1267-1278, 2005.

[51] P. S. Sever, B. Dahlöf, N. R. Poulter et al., "Prevention of coronary and stroke events with atorvastatin in hypertensive patients who have average or lower-than-average cholesterol concentrations, in the Anglo-Scandinavian Cardiac Outcomes Trial-Lipid Lowering Arm (ASCOT-LLA): a multicentre randomised controlled trial," The Lancet, vol. 361, no. 9364, pp. 1149-1158, 2003.

[52] H. M. Colhoun, D. J. Betteridge, P. N. Durrington et al., "Primary prevention of cardiovascular disease with atorvastatin in type 2 diabetes in the Collaborative Atorvastatin Diabetes Study (CARDS): multicentre randomised placebo-controlled trial," The Lancet, vol. 364, no. 9435, pp. 685-696, 2004. 
[53] P. M. Ridker, E. Danielson, F. A.H. Fonseca et al., "Rosuvastatin to prevent vascular events in men and women with elevated C-reactive protein," The New England Journal of Medicine, vol. 359, no. 21, pp. 2195-2207, 2008.

[54] P. M. Ridker, E. Danielson, F. A. Fonseca et al., "Reduction in C-reactive protein and LDL cholesterol and cardiovascular event rates after initiation of rosuvastatin: a prospective study of the JUPITER trial," The Lancet, vol. 373, no. 9670, pp. 1175$1182,2009$.

[55] J. C. LaRosa, S. M. Grundy, D. D. Waters et al., "Intensive lipid lowering with atorvastatin in patients with stable coronary disease," The New England Journal of Medicine, vol. 352, no. 14, pp. 1425-1435, 2005.

[56] J. C. La Rosa, S. M. Grundy, J. J. Kastelein, J. B. Kostis, and H. Greten, "Treating to New Targets (TNT) Steering Committee and Investigators. Safety and efficacy of atorvastatin induced very low density lipoprotein cholesterol levels in patients with coronary heart disease (a post hoc analysis of the Treating to New Targets (TNT) Study," American Journal of Cardiology, vol. 100, pp. 747-752, 2007.

[57] J. C. LaRosa, P. C. Deedwania, J. Shepherd et al., "Comparison of $80 \mathrm{mg}$ versus $10 \mathrm{mg}$ of atorvastatin on occurrence of cardiovascular events after the first event (from the TNT trial)," American Journal of Cardiology, vol. 105, no. 3, pp. 283 287, 2010.

[58] G. G. Schwartz, A. G. Olsson, M. D. Ezekowitz et al., "Effects of atorvastatin on early recurrent ischemic events in acute coronary syndromes the MIRACL study: a randomized controlled trial," Journal of the American Medical Association, vol. 285, no. 13, pp. 1711-1718, 2001.

[59] C. P. Cannon, E. Braunwald, C. H. McCabe et al., "Intensive versus moderate lipid lowering with statins after acute coronary syndrome," The New England Journal of Medicine, vol. 350, no. 15, pp. 1495-1504, 2004.

[60] P. M. Ridker, C. P. Cannon, D. Morrow et al., "C-reactive protein levels and outcomes after statin therapy," The New England Journal of Medicine, vol. 352, no. 1, pp. 20-28, 2005.

[61] K. K. Ray, D. A. Morrow, M. S. Sabatine et al., "Long-term prognostic value of neopterin: a novel marker of monocyte activation in patients with acute coronary syndrome," Circulation, vol. 115, no. 24, pp. 3071-3078, 2007.

[62] V. Fuster, Ed., In the AHA Guidelines and Scientific Statements Handbook, chapter 2, 2009.

[63] S. A. Murphy, C. P. Cannon, S. D. Wiviott, C. H. McCabe, and E. Braunwald, "Reduction in recurrent cardiovascular events wit intensive-lowering statin therapy compared with moderate-lipid lowering statin therapy after acute coronary syndromes from the PROVE-IT. TIMI 22 trial," Journal of the American College of Cardiology, vol. 54, no. 25, pp. 2358-2362, 2009.

[64] P. Amarenco, J. Bogousslavsky, A. Callahan III et al., "Highdose atorvastatin after stroke or transient ischemic attack," The New England Journal of Medicine, vol. 355, no. 6, pp. 549-559, 2006.

[65] F. Antonini-Canterin, L. M. Moura, R. Enache et al., "Effect of hydroxymethylglutaryl coenzyme-a reductase inhibitors on the long-term progression of rheumatic mitral valve disease," Circulation, vol. 121, no. 19, pp. 2130-2136, 2010.

[66] M. Vasa, S. Fichtlscherer, K. Adler et al., "Increase in circulating endothelial progenitor cells by statin therapy in patients with stable coronary artery disease," Circulation, vol. 103, no. 24, pp. 2885-2890, 2001.
[67] U. Landmesser, N. Engberding, F. H. Bahlmann et al., "Statininduced improvement of endothelial progenitor cell mobilization, myocardial neovascularization, left ventricular function, and survival after experimental myocardial infarction requires endothelial nitric oxide synthase," Circulation, vol. 110, no. 14, pp. 1933-1939, 2004.

[68] S. Dimmeler, "Regulation of bone marrow-derived vascular progenitor cell mobilization and maintenance," Arteriosclerosis, Thrombosis, and Vascular Biology, vol. 30, no. 6, pp. 10881093, 2010.

[69] O. N. Akram, A. Bernier, F. Petrides, G. Wong, and G. Lambert, "Beyond LDL cholesterol, a new role for pcsk9," Arteriosclerosis, Thrombosis, and Vascular Biology, vol. 30, no. 7, pp. 1279-1281, 2010.

[70] E. Morales-Villegas, Ed., Atlas de Riesgo Cardio Metabólico Total, Atheros, Aguascalientes, Mexico, 1st edition, 2009. 


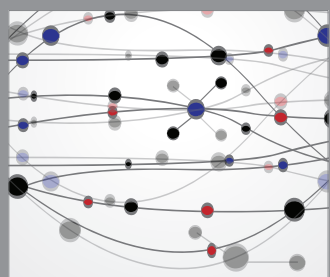

The Scientific World Journal
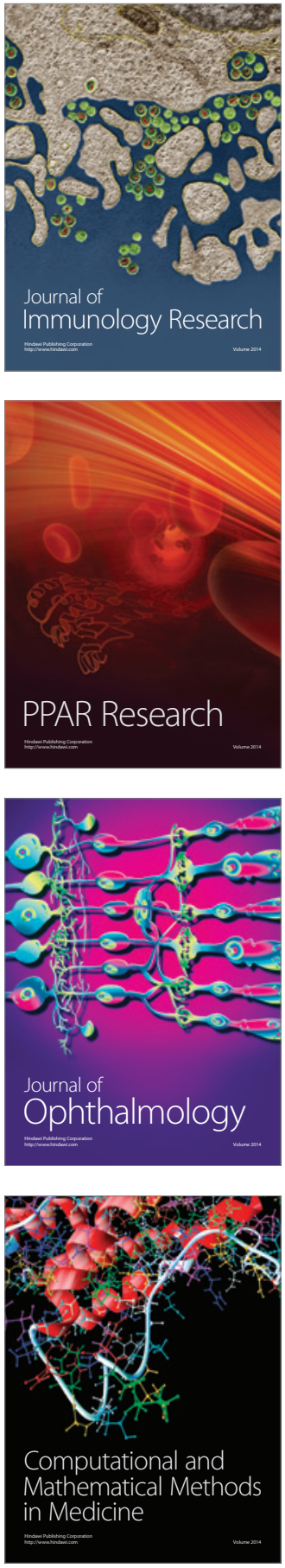

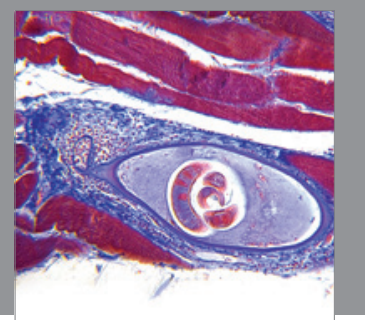

Gastroenterology

Research and Practice
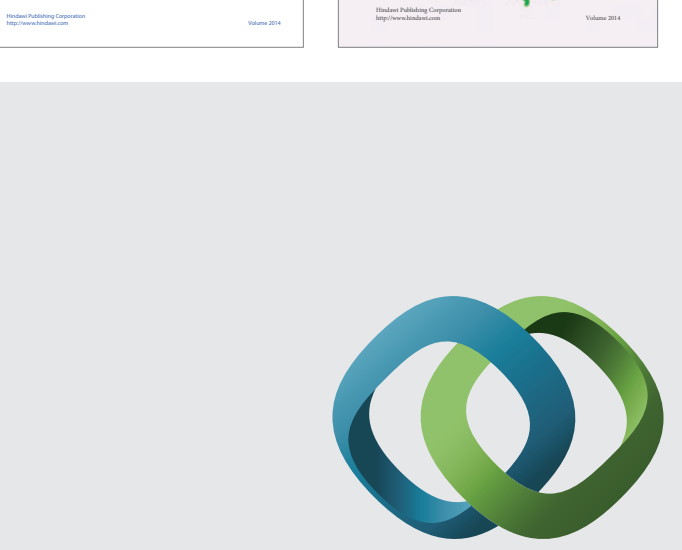

\section{Hindawi}

Submit your manuscripts at

http://www.hindawi.com
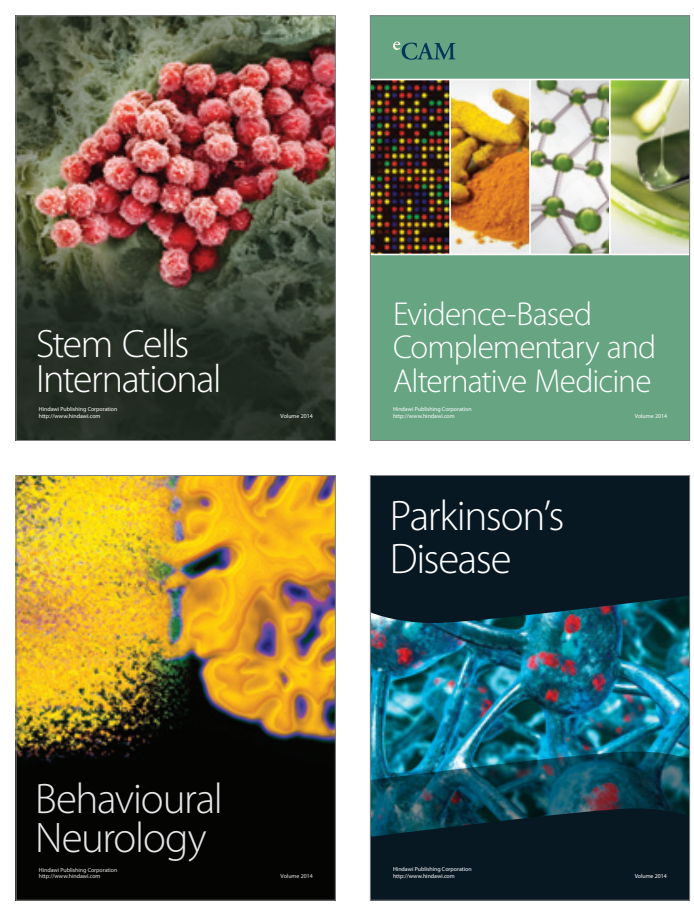

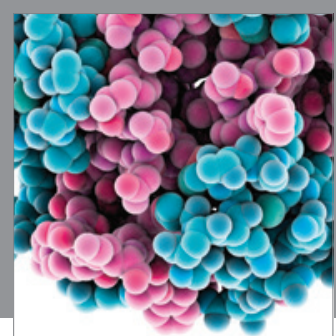

Journal of
Diabetes Research

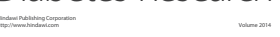

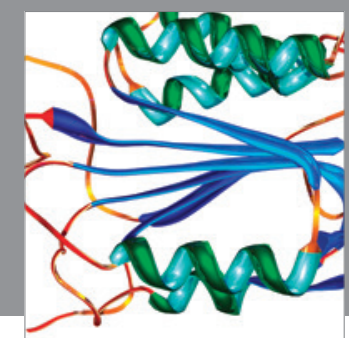

Disease Markers
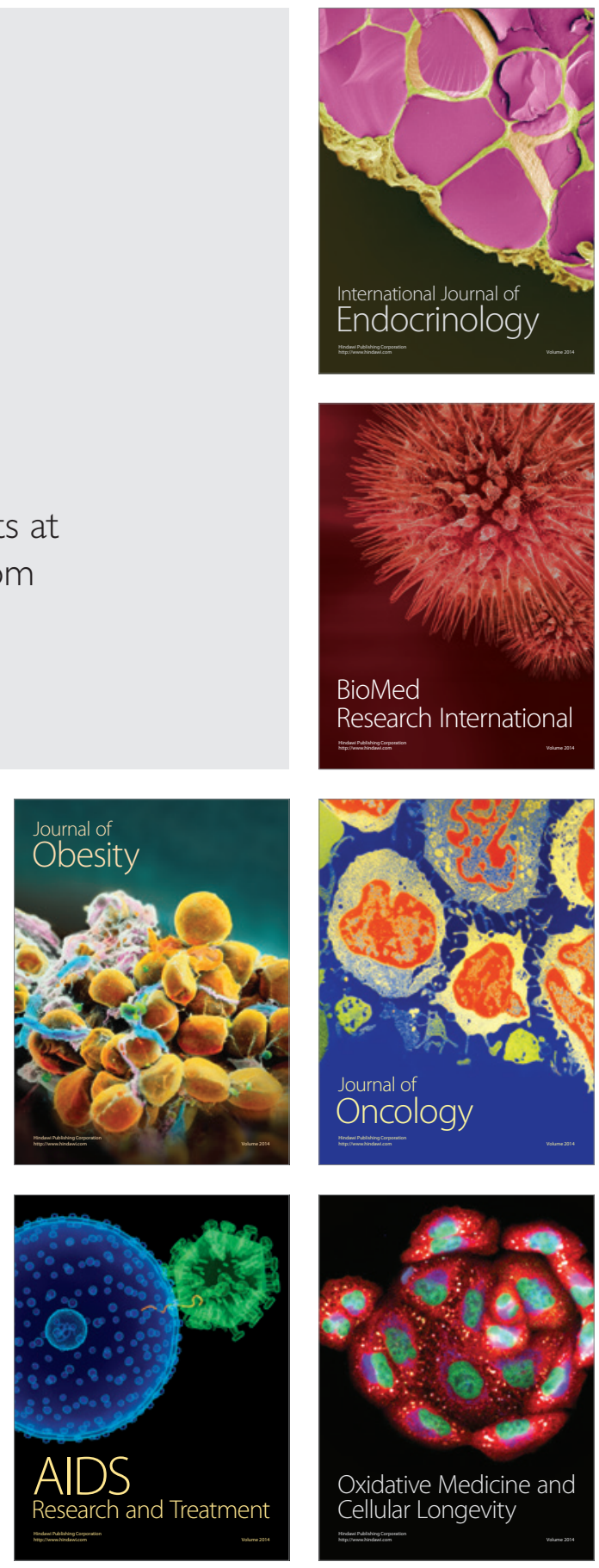